\title{
Media Komunikasi Visual Sebagai Penunjang Promosi Pada SMK Multimedia Mandiri
}

\author{
Lusyani Sunarya* ${ }^{*}$, Maimunah ${ }^{2}$, Ratna Sari ${ }^{3}$ \\ 1,2,3 Program Studi Teknik Informatika STMIK Raharja \\ E-mail: ${ }^{* 1}$ lusyani@ raharja.info, ${ }^{2}$ maimunah@ raharja.info, ${ }^{3}$ ratna@ raharja.info
}

\begin{abstract}
Abstrak
Saat ini media komunikasi visual berkembang sangat pesat dan sering kali digunakan sebagai media penunjang promosi untuk menyampaikan informasi seefektif mungkin. Media komunikasi visual dapat diimplementasikan di suatu sekolah untuk mempromosikan dan memperkenalkan lingkungan sekolah ke masyarakat luas agar menarik minat calon siswa/i yang akan mendaftar di tahun ajaran selanjutnya, seperti yang dimiliki oleh SMK Multimedia Mandiri. Sebelumnya SMK Multimedia Mandiri sudah mempunyai media promosi berupa brosur, namun brosur yang terdapat di SMK Multimedia Mandiri dirasa kurang efektif untuk mempromosikan dan memberikan informasi mengenai sekolah karena hanya menggunakan 1 media saja sehingga kurang menarik perhatian masyarakat. Dengan adanya penelitian ini maka dikembangkanlah media promosi lain berupa baliho, banner, flyer, pamflet, papan nama, poster, dan spanduk yang diharapkan dapat menarik perhatian masyarakat untuk mengetahui informasi SMK Multimedia Mandiri, meningkatkan jumlah peserta didik di tahun ajaran selanjutnya, dan agar SMK Multimedia Mandiri dapat dikenal di lingkungan masyarakat yang lebih luas. Penelitian kali ini dibuat dengan menggunakan metode observasi, metode wawancara, dan studi pustaka. Pengembangan media komunikasi visual yang akan dibuat ini menggunakan aplikasi CorelDRAW X7.
\end{abstract}

Kata Kunci-Desain, Informasi dan Promosi, Sekolah

\begin{abstract}
Currently the visual communication media is growing very rapidly and often used as a promotional support media to convey information as effectively as possible. Visual communication media can be implemented in a school to promote and introduce the school environment to the wider community to attract the attention of prospective students who will enroll in the next academic year, such as those owned by Multimedia Mandiri Vocational Highschool. Previously the vocational highschool already has a promotional media in the form of brochures, but the brochure contained is felt less effective to promote and provide information about the school because it uses only 1 media so it attracts less attention of the public. With this research, then developed other promotion media in the form of billboards, banners, flyers, pamphlets, signboards, posters, and banners that are expected to attract public attention to Multimedia Mandiri Vocational Highschool information, increasing the number of students in the next academic year, Multimedia Mandiri Vocational Highschool can be recognized in the wider society. This research was made using data collection method, design concept, and SWOT analysis. The development of visual communication media will be made using CorelDRAW X7 application.
\end{abstract}

Keywords - Design, Information and Promotion, School 


\section{PENDAHULUAN}

Perkembangan media promosi saat ini berkembang cukup pesat, media komunikasi visual sangat dibutuhkan dalam memasarkan suatu perusahaan, instansi, ataupun suatu lembaga, karena melalui media komunikasi visual dapat menyampaikan informasi dan promosi dengan mudah dan memenuhi kebutuhan audience akan informasi yang ingin di ketahuinya. Melalui media komunikasi yang disampaikan mampu menarik minat audience pada produk atau jasa yang dipasarkan.

Promosi merupakan kegiatan yang dilakukan oleh perusahaan untuk memberikan informasi mengenai manfaat produk dan juga sebagai alat untuk mempengaruhi konsumen untuk membeli atau menggunakan jasa sesuai dengan kebutuhan ${ }^{[1]}$.

Promosi merupakan kegiatan yang mempunyai tujuan memperkenalkan produk yang berupa barang maupun jasa ke masyarakat luas agar menarik minat masyarakat untuk mengetahui, membeli, dan menggunakan produk atau jasa yang disediakan. Promosi dapat menggunakan beberapa media untuk melakukan promosi produk atau jasa, yaitu media cetak atau media komunikasi visual dan media elektronik.

Media komunikasi visual merupakan suatu proses penyampaian pesan atau informasi yang disampaikan kepada orang lain dengan menggunakan media gambar yang hanya dapat dibaca dengan alat penglihatan. Media komunikasi visual umumnya mengkombinasikan desain grafis, gambar, ilustrasi, lambang, seni, tipografi, dan warna untuk penyampaiannya. Saat ini media komunikasi visual sudah memiliki banyak bentuk, salah satunya adalah media cetak. Media cetak adalah sebuah media yang digunakan untuk menyampaikan informasi ke masyarakat luas secara fisik. Promosi produk atau jasa menggunakan media cetak berbeda dengan cara melakukan promosi menggunakan media elektronik. Selain digunakan oleh perusahaan, promosi juga banyak digunakan di dalam dunia pendidikan, contohnya yaitu untuk mempromosikan sebuah sekolah. Banyak usaha yang perlu dilakukan dalam persaingan dengan sekolah lain agar mendapat lebih banyak siswa/i baru yang mendaftar di setiap tahunnya seperti yang terdapat pada SMK Multimedia Mandiri.

Sekolah Menengah Kejuruan (SMK) merupakan salah satu tingkat pendidikan menengah yang memiliki tujuan untuk mempersiapkan siswa/i nya agar siap bekerja. Sekolah Menengah Kejuruan (SMK) sendiri mempunyai banyak arti yang berbeda-beda, akan tetapi mempunyai makna yang sama. Sekolah Menengah Kejuruan (SMK) merupakan lembaga pendidikan yang mempunyai potensi untuk mempersiapkan SDM yang dapat digunakan dalam dunia kerja, karena materi teori dan praktik yang bersifat aplikatif sudah diberikan sejak pertama masuk SMK, dengan harapan lulusan SMK memiliki kompetensi yang sesuai dengan kebutuhan dunia kerja ${ }^{[2]}$. SMK Multimedia Mandiri adalah sekolah menengah kejuruan yang berlokasi di Jl. Raya Kedoya No. 2, RT005/RW004, Kedoya Selatan, Kebun Jeruk, Jakarta, yang menyediakan jurusan Teknik Komputer Jaringan (TKJ) yang diharapkan mampu menampung calon siswa/i yang mempunyai ketertarikan tinggi dalam ilmu komputer.

Permasalahan yang terdapat pada SMK Multimedia Mandiri saat ini adalah media promosi yang digunakan sebelumnya terasa kurang efisien karena hanya menggunakan brosur sebagai media promosinya, maka dari itu dibutuhkan pengembangan media penunjang promosi sekolah yang berbentuk media komunikasi visual seperti baliho, banner, flyer, pamflet, papan nama, poster, dan spanduk. Selain itu, pihak sekolah menginginkan adanya redesign media brosur yang sudah ada sebelumnya dengan alasan ingin menyegarkan tampilan visualnya agar terlihat lebih menarik dan informasinya lebih update sesuai dengan perkembangan sekolah saat ini.

Pengembangan media komunikasi visual sangat dibutuhkan SMK Multimedia Mandiri saat ini, untuk membantu bagian pemasaran dalam mempromosikan dan memperkenalkan identitas SMK Multimedia Mandiri kepada masyarakat, media komunikasi visual ini nantinya akan diberikan dan di informasikan ke sekolah-sekolah SMP, selain itu diberikan juga saat presentasi internal dengan orang tua murid yang ingin mendaftar ke SMK Multimedia Mandiri. Melalui media komunikasi visual yang dirancang dapat menarik minat calon siswa/i baru untuk 
bergabung di SMK Multimedia Mandiri, dan SMK Multimedia Mandiri semakin di kenal masyarakat luas.

Literature Review

Dalam pembuatan penelitian ini perlu dilakukan studi pustaka untuk dijadikan sebagai referensi dari penelitian-penelitian yang sudah ada sebelumnya, diantaranya:

1. Penelitian yang dibuat oleh Dewi Immaniar, Reni Mulyani, dan Fitria Arnita yang berjudul "Desain Komunikasi Visual Sebagai Sarana Promosi Perguruan Tinggi". Dalam penelitian tersebut menjelaskan tentang desain komunikasi visual sebagai sarana promosi adalah sebuah project yang mencoba memaparkan sebuah proses perancangan media untuk memberikan informasi yang berupa suatu pesan berkenaan dengan usaha promosi sebuah institusi yang bergerak dalam bidang pendidikan ${ }^{[3]}$.

2. Penelitian yang dibuat oleh Triyono, Kemal Salahuddin, dan Hendi Setiawan yang berjudul "Desain Komunikasi Visual Penunjang Event Wisuda". Dalam penelitian tersebut menjelaskan tentang penyelenggaraan event Wisuda Perguruan Tinggi Raharja pada tahun sebelumnya bahwa dalam setiap penyelenggaraan acara selalu membutuhkan sarana media komunikasi visual dengan desain yang baru dan juga menarik sebagai penunjang suksesnya event tersebut ${ }^{[4]}$.

3. Penelitian yang dibuat oleh Lusyani Sunarya, Desi Wahyu Kartika Sari, dan Pajrin Yurika Sahara yang berjudul "Perancangan Media Iklan Sebagai Penunjang Informasi dan Promosi Pada Hotel Sitamiang 2 Bogor". Dalam penelitian tersebut bertujuan untuk merancang media berbasis audio visual yang menarik dan efektif, terutama dalam menyampaikan informasi dan promosi entang hal-hal yang berhubungan dengan Hotel Sitamiang 2 Bogor ${ }^{[5]}$.

4. Penelitian yang dibuat oleh Dewi Immaniar Desrianti, Anita B Wandanaya, dan Asih Sumaryani yang berjudul "Perancangan Media Katalog Sebagai Penunjang Informasi dan Promosi Pada CV. Zero Store". Dalam penelitian tersebut menjelaskan tentang salah satu cara untuk meningkatkan pendapatan dan menarik konsumen yang loyal yaitu dengan menggunakan media komunikasi visual yang secara tidak langsung dapat diharapkan nilai efektifitasnya dalam memberikan informasi mengenai programprogram pemasaran produk ${ }^{[6]}$.

5. Penelitian yang dibuat oleh Anita B Wandanaya, Dewi Immaniar, dan Maryana Astuti yang berjudul "Design Visualisasi Logo Sebagai Identity Programs di Divisi Raharja Enrichment Centre". Dalam penelitian tersebut menjelaskan tentang salah satu hal penting dalam suatu media visual lembaga institusi terhadap publik yaitu sebuah identitas logo. Identitas logo sendiri memiliki arti sebagai identitas yang mewakili gambaran sebuah lembaga institusi ${ }^{[7]}$.

6. Penelitian yang dibuat oleh David Christian, Ani Wijayanti S, dan Bramantijo yang berjudul "Perancangan Media Komunikasi Visual Sebagai Sarana Promosi Domain Budget Pizza di Surabaya". Dalam penelitian tersebut menjelaskan tentang perancangan media promosi yang baik dan benar agar menarik minat masyarakat untuk mengetahui serta membeli produk-produk yang ada pada Domain Budget Pizza sehingga dapat menaikkan angka penjualan ${ }^{[4]}$.

7. Penelitian yang dibuat oleh Kartika Chandra Paramitha yang berjudul "Perancangan Media Komunikasi Visual Untuk Promosi Wisata Paralayang di Batu". Dalam penelitian tersebut menjelaskan tentang pembuatan desain komunikasi visual berupa billboard, brosur, dan majalah dengan menggunakan tema adventure untuk mempromosikan wisata paralayang yang ada di Batu ke masyarakat ${ }^{[5]}$.

8. Penelitian yang dibuat oleh Antony Tjandra Joedyanto, Obed Bima Wicandra, dan Asthararianty yang berjudul "Perancangan Promosi Hotel Varna Surabaya". Dalam penelitian tersebut menjelaskan tentang perancangan komunikasi visual yang dibuat untuk mempromosikan Hotel Varna dengan efektif dan efisien untuk meningkatkan target marketnya dengan menggunakan media cetak ${ }^{[6]}$. 
9. Penelitian yang dibuat oleh Resita Lifenia yang berjudul "Perancangan Media Promosi Triwulan Event Artotel Surabaya". Dalam penelitian ini menjelaskan tentang perancangan komunikasi visual sebagai sarana promosi untuk memperkenalkan Triwulan Event ke masyarakat agar datang ke Artotel untuk melihat rangkaian acaranya menggunakan brosur, gantungan kunci, kalender, placemat, poster, dan $x$-banner ${ }^{[7]}$.

\section{METODE PENELITIAN}

Metode penelitiaan yang digunakan dalam pembuatan penelitian ini menggunakan metode pengumpulan data, konsep desain, dan analisa SWOT. Pengumpulan data yang dilakukan dalam penelitian ini menggunakan metode wawancara dan interview, data dan informasi yang diperoleh dari metode wawancara dan interview dilakukan melalui tanya jawab langsung dengan stakeholder Bapak Slamet R selaku kepala sekolah Sekolah Menengah Kejuruan (SMK) Multi Media Mandiri. Selanjutnya melakukan observasi dengan mendatangi langsung tempat penelitian di Sekolah Menengah Kejuruan (SMK) Multi Media Mandiri. Data dan hal-hal yang diperlukan dalam pembuatan media komunikasi visual yang akan dibuat telah didapatkan dari metode observasi tersebut. Tahap berikutnya ialah melakukan studi literatur dengan mencari data-data yang diperlukan sebagai materi acuan dan referensi, data tersebut diperoleh dari jurnal-jurnal yang telah terbit sebelumnya dan yang telah dicantumkan ke dalam literature review. Selain literature review, pengumpulan data juga dilakukan dengan cara studi pustaka, data yang diperoleh melalui studi pustaka yaitu merupakan materi-materi yang digunakan sebagai bahan referensi dan acuan dari berbagai sumber.

Setelah metode pengumpulan data telah selesai dilakukan, selanjutnya yang akan dilakukan adalah tahap metode konsep desain. Di bawah ini merupakan penjabaran dari metode konsep desain yang telah dilakukan dan dibuat:

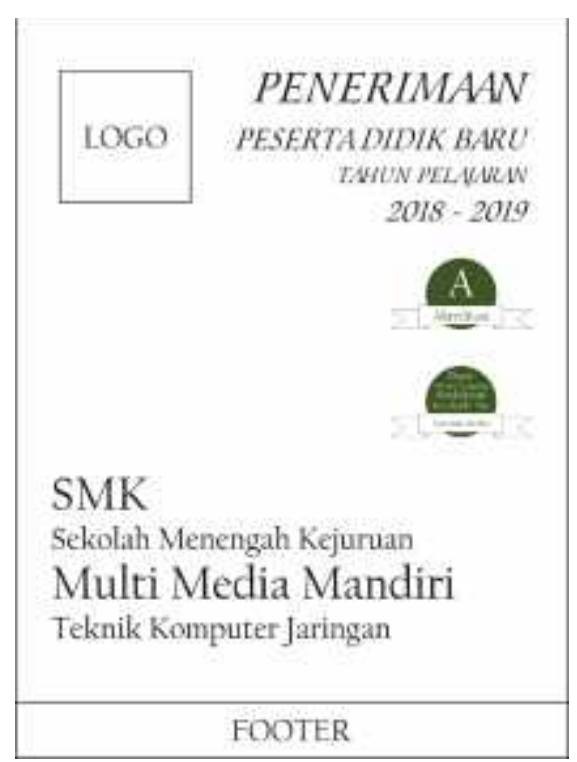

Gambar 1. Konsep desain baliho

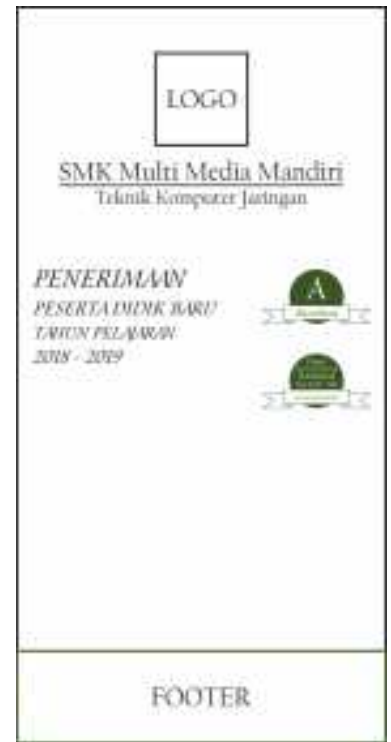

Gambar 2. Konsep desain banner

Gambar di atas adalah konsep desain baliho dan banner yang telah dibuat, apabila dilihat layout baliho pada gambar 1. Terdapat logo SMK Multimedia Mandiri di sebelah kiri bagian atas sehingga logo dapat lebih mudah dilihat dan dikenali. Logo akreditasi dan pemberian beasiswa terletak di sebelah kanan, di bawah kalimat "Penerimaan Peserta Didik Baru" sehingga pembaca akan langsung melihat akreditasi \& informasi mengenai pemberian beasiswa setelah membaca kalimat pertama. Terakhir di bagian bawah terdapat footer yang dapat berisi catatan kaki atau informasi lain yang dibutuhkan pembaca. Sedangkan apabila dilihat layout banner pada gambar 2. Tidak terdapat banyak perbedaan desain dengan konsep 
baliho sebelumnya namun peletakan logo pada banner terdapat di bagian tengah, layout seluruhnya hampir sama dengan konsep desain baliho.

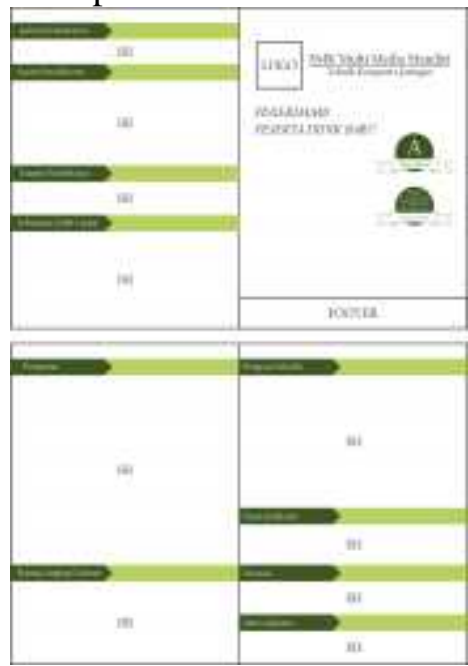

Gambar 3. Konsep desain brosur

Gambar di atas merupakan layout dari konsep desain brosur yang telah dibuat pada penelitian ini, pada lembar pertama terdapat cover yang memiliki layout sama dengan konsep desain baliho yang telah dibuat sebelumnya, lalu pada lembar kedua terdapat informasi mengenai jadwal pendaftaran, syarat pendaftaran, lokasi pendaftaran, dan beberapa informasi lain yang dibutuhkan si pembaca, pada lembaran brosur ketiga terdapat kata pengantar dan sambutan serta jangkauan ruang lingkup lulusan, di dalam lembaran brosur terakhir terdapat informasi mengenai program sekolah, ekstrakurikuler, prestasi sekolah, dan mitra industri yang bekerja sama dengan sekolah.

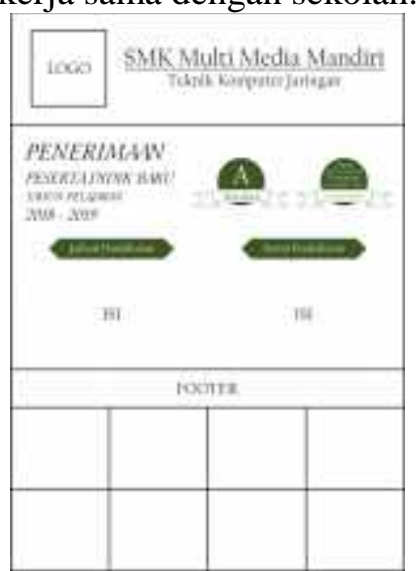

Gambar 4. Konsep desain flyer

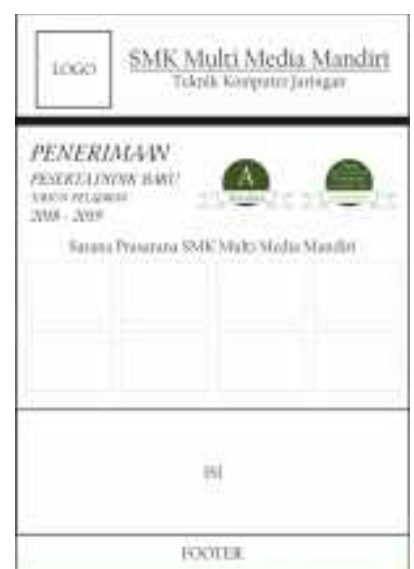

Gambar 5. Konsep desain pamflet

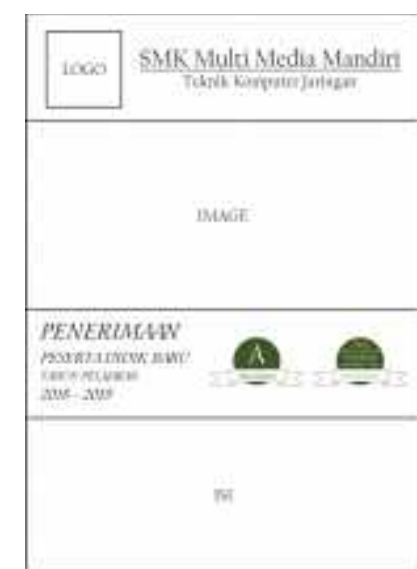

Gambar 6. Konsep desain poster

Ketiga gambar di atas merupakan konsep desain yang telah dibuat untuk desain flyer, pamflet, dan poster terdapat beberapa persamaan dalam konsep desain di antara tiga media tersebut yaitu peletakan logo yang berada di sebelah kiri bagian atas dan tepat di sebelah kanan logo terdapat nama sekolah dan jurusan dari kejuruan, informasi penerimaan siswa baru pun juga terletak di bagian bawah logo sebelah kiri dan di sebelah kanan informasi penerimaan siswa baru terdapat informasi mengenai akreditasi sekolah. Dalam konsep desain flyer terdapat kumpulan foto sarana dan prasarana dari sekolah, sedangkan pada desain pamflet terdapat informasi mengenai syarat pendaftaran dan jadwal pendaftaran. Sedangkan, di dalam konsep desain poster masih terdapat kesamaan dengan konsep desain sebelumnya yaitu peletakan logo sekolah atau logo yayasan yang berada di sebelah kiri bagian atas dan di samping kanan logo terdapat nama sekolah dengan jurusan dari sekolah kejuruan. Lalu di bagian bawah logo 
terdapat gambar yang nantinya dapat mewakili informasi yang ingin disampaikan, di bawah gambar terdapat informasi mengenai penerimaan siswa tahun ajaran baru dan logo akreditasi sekolah dan di bagian terakhir terdapat footer yang mungkin nantinya dapat berisi alamat sekolah maupun informasi lain yang ingin disampaikan.

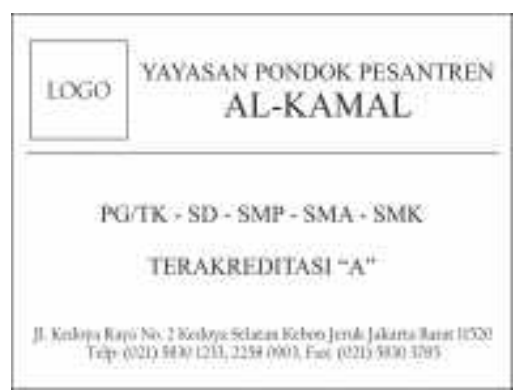

Gambar 7. Konsep desain papan nama

Konsep desain papan nama yang nantinya akan diletakkan di depan gerbang sekolah apabila sudah jadi mempunyai logo yayasan atau sekolah di bagian kiri atas dan terdapat nama yayasan di sebelah kanan logo, lalu terdapat tingkatan pendidikan yang ada pada yayasan mulai dari playgoup/TK, Sekolah Dasar (SD), Sekolah Menengah Pertama (SMP), Sekolah Menengah Atas (SMA), dan Sekolah Menengah Kejuruan (SMK) dengan akreditasi yang sudah diberikan, serta di bagian bawah papan nama terdapat informasi mengenai alamat sekolah.

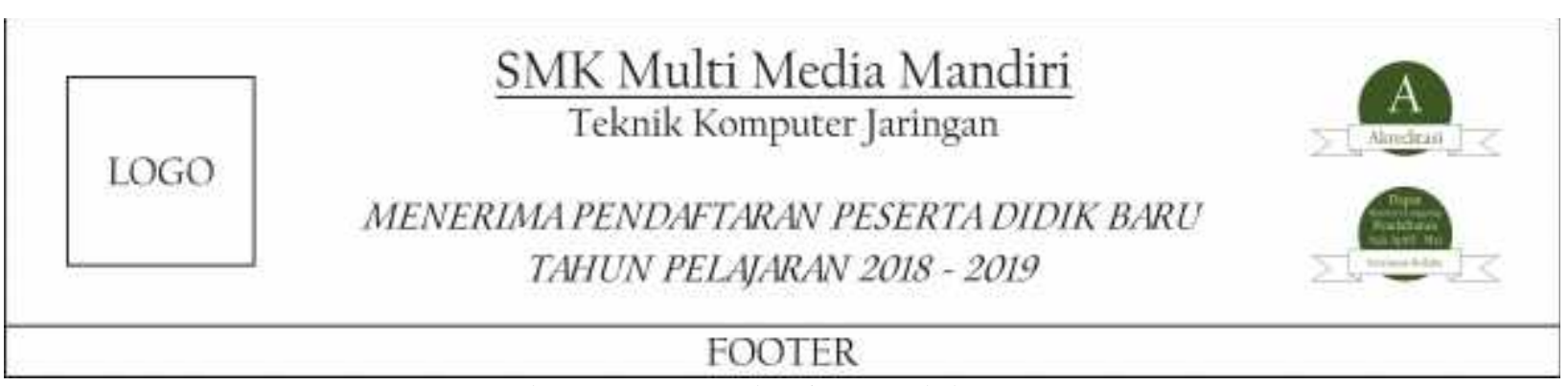

Gambar 8. Konsep desain spanduk

Pada gambar 8 adalah konsep desain dari media komunikasi visual spanduk yang akan dibuat, terdapat logo yayasan di sebelah kiri spanduk dan di bagian paling kanan terdapat logo akreditasi, di bagian tengah terdapat nama sekolah dan jurusan dari kejuruan sekolah, informasi mengenai penerimaan dan pendaftaran peserta didik baru juga ada di bagian bawah nama sekolah, serta di bagian footer dapat diisi dengan informasi mengenai alamat sekolah.

Selain metode pengumpulan data dan metode konsep desain, selanjutnya adalah melakukan metode analisa SWOT. SWOT adalah metode perencanaan strategis yang digunakan untuk mengevaluasi kekuatan (strengths), kelemahan (weaknesses), peluang (opportunities), dan ancaman (threats) dalam suatu proyek atau suatu spekulasi bisnis. Keempat faktor itulah yang membentuk akronim SWOT (strengths, weaknesses, opportunities, dan threats). Langkah penelitian ini akan menerangkan bagaimana analisis dilakukan, mulai dari data mentah yang ada sampai pada hasil penelitian yang dicapai. Dalam penelitian ini, langkah-langkah analisis data dilakuka sebagai berikut:

1. Melakukan pengklasifikasian data, faktor apa saja yang menjadi kekuatan dan kelemahan sebagai faktor internal organisasi, peluang dan ancaman sebagai faktor eksternal organisasi. Pengklasifikasian ini akan menghasilkan tabel informasi SWOT.

2. Melakukan analisis SWOT yaitu membandingkan antara faktor eksternal Peluang (Opportunities) dan Ancaman (Threats) dengan faktor internal organisasi Kekuatan (Strengths) dan Kelemahan (Weakness). 
3. Dari hasil analisis kemudian diinterpretasikan dan dikembangkan menjadi keputusan pemilihan strategi yang memungkinkan untuk dilaksanakan. Strategi yang dipilih biasanya hasil yang paling memungkinkan (paling positif) dengan resiko dan ancaman yang paling kecil.

Table 1. Analisa SWOT

\begin{tabular}{|c|c|c|}
\hline & Peluang (Opportunity) & Ancaman (Threat) \\
\hline $\begin{array}{c}\text { MATRIX SWOT } \\
\text { SMK Multi Media Mandiri }\end{array}$ & $\begin{array}{l}\text { 1. } \begin{array}{l}\text { Dukungan pemerintah dalam } \\
\text { melengkapi sarana dan } \\
\text { prasarana }\end{array} \\
\text { 2. Kesesuaian sarana dan } \\
\text { prasarana sekolah dengan } \\
\text { tuntutan potensi daerah dan } \\
\text { perkembangan IPTEK serta } \\
\text { IMTAQ } \\
\text { 3. Tuntutan masyarakat } \\
\text { terhadap lulusan yang } \\
\text { berkualitas } \\
\text { 4. Sponsor/perusahaan/yayasan } \\
\text { 5. } \text { Dukungan orang tua tinggi }\end{array}$ & $\begin{array}{ll}\text { 1. } & \text { Lembaga pendidikan } \\
\text { sejenis } \\
\text { 2. Lingkungan social } \\
\text { sekolah }\end{array}$ \\
\hline Kekuatan (Strenght) & S-O Strategies & S-T Strategies \\
\hline $\begin{array}{l}\text { 1. Motivasi guru dan siswa } \\
\text { 2. Fasilitas laboratorium } \\
\text { 3. Hubungan yang baik } \\
\text { antara guru dengan guru } \\
\text { ataupun guru dengan } \\
\text { siswa metode } \\
\text { 4. Pendekatan yang } \\
\text { mengajar guru yar } \\
\text { bervariasi } \\
\text { 5. Pembiayaan }\end{array}$ & $\begin{array}{l}\text { S1-O1 } \\
\text { Meningkatkan sarana dan } \\
\text { prasarana sehingga guru dan } \\
\text { siswa lebih termotivasi } \\
\text { S5-O4 } \\
\text { Mengadakan event-event sekolah } \\
\text { dan pengajuan sponsor } \\
\text { S4-O3 } \\
\text { Membangun lulusan siswa/i yang } \\
\text { berkualitas dengan pendekatan } \\
\text { belajar yang bervariasi }\end{array}$ & $\begin{array}{l}\text { S1-T2 } \\
\text { Guru memotivasi siswa/i } \\
\text { agar tidak terpengaruh } \\
\text { dengan kondisi lingkungan } \\
\text { sosial yang negative } \\
\text { S5-T5 } \\
\text { Teknologi yang terus } \\
\text { berkembang dan harga yang } \\
\text { meningkat memotivasi pihak } \\
\text { sekolah untuk memberikan } \\
\text { fasilitas lab dengan baik }\end{array}$ \\
\hline Kelemahan (Weakness) & W-O Strategies & W-T Strategies \\
\hline $\begin{array}{ll}\text { 1. } & \text { Rekrutmen guru dan } \\
\text { staff } \\
\text { 2. } \\
\text { 3. } \\
\text { Keadaan guru } \\
\text { baru/pindahan } \\
\text { 4. } \\
\text { 5PJS ketenaga kerjaan } \\
\text { 5edung sekolah }\end{array}$ & $\begin{array}{l}\text { W3-O1 } \\
\text { Siswa baru/pindahan tetap akan } \\
\text { mendapatkan dana bantuan dari } \\
\text { KJS PLUS } \\
\text { W4-O4 } \\
\text { Tenaga pengajar mendapatkan } \\
\text { jaminan kesehatan dan } \\
\text { ketenagakerjaan }\end{array}$ & $\begin{array}{l}\text { W5-T3 } \\
\text { Gedung sekolah sebagai } \\
\text { pusat berbagai kegiatan } \\
\text { dapat menjadikan kegiatan } \\
\text { tersebut sebagai ajang } \\
\text { promosi sekolah } \\
\text { W1-T4 } \\
\text { Guru dan staff yang ahli } \\
\text { dalam bidangnya sehingga } \\
\text { dapat bersaing dengan } \\
\text { lembaga pendidikan yang } \\
\text { sejenis }\end{array}$ \\
\hline
\end{tabular}

\section{HASIL DAN PEMBAHASAN}

Setelah melaksanakan metode penelitian maka dibuatlah perancangan media promosi yang dibutuhkan SMK Multi Media Mandiri berupa baliho, banner, brosur, flyer, pamflet, papan nama, poster, dan spanduk yang akan digunakan untuk menunjang promosi SMK Multi Media Mandiri agar mampu bersaing dengan sekolah lain dalam meningkatkan jumlah peserta didik yang akan mendaftar di tahun-tahun berikutnya. Konsep yang digunakan dalam 
pembuatan media promosi SMK Multi Media Mandiri ini berupa ide-ide yang diambil menurut data yang didapat dari SMK Multi Media Mandiri lalu akan dibuat menjadi media komunikasi visual yang mencerminkan gambaran SMK Multi Media Mandiri, selain itu data-data yang berupa gambar akan ditambahkan ke dalam media komunikasi visual yang sudah dibuat untuk memperlihatkan gambaran SMK Multi Media Mandiri sehingga bisa meningkatkan target siswa/i baru yang akan mendaftar.

Berikut 8 media yang telah dirancang untuk menunjang promosi pada SMK Multi Media Mandiri.

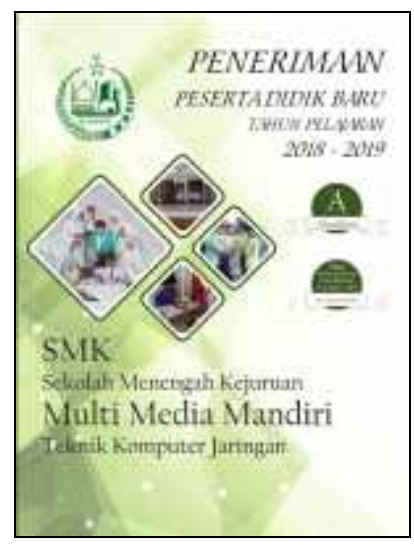

Gambar 9. Baliho

Gambar 9 adalah baliho merupakan salah satu media promosi yang mempunyai tujuan untuk menginformasikan kepada masyarakat luas bahwa SMK Multimedia Mandiri sedang mengadakan penerimaan peserta didik baru tahun ajaran 2018 - 2019. Selain penerimaan peserta didik baru, terdapat juga status akreditasi sekolah SMK Multimedia Mandiri dan informasi mengenai penawaran beasiswa dengan syarat dan ketentuan yang berlaku. Baliho dibuat dengan ukuran 6 X 4 M menggunakan bahan Flexi Korea.

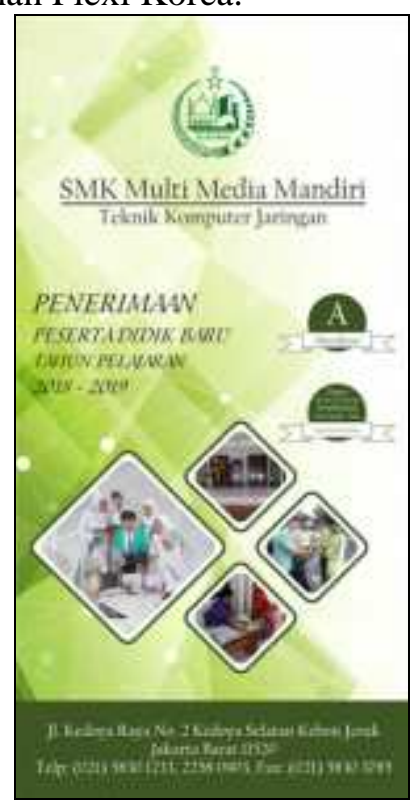

Gambar 10. Banner

Gambar 10 adalah banner merupakan media promosi yang merupakan bentuk sederhana dari baliho. Banner pada umumnya berisi mengenai suatu informasi dan dibuat dengan bentuk portrait. Informasi yang terdapat dalam banner tersebut antara lain penerimaan peserta didik baru, status akreditasi, beasiswa, alamat sekolah, serta nomor telepon yang dapat dihubungi. Banner dibuat menggunakan bahan Flexi Korea dengan ukuran 60 X 160 CM. 


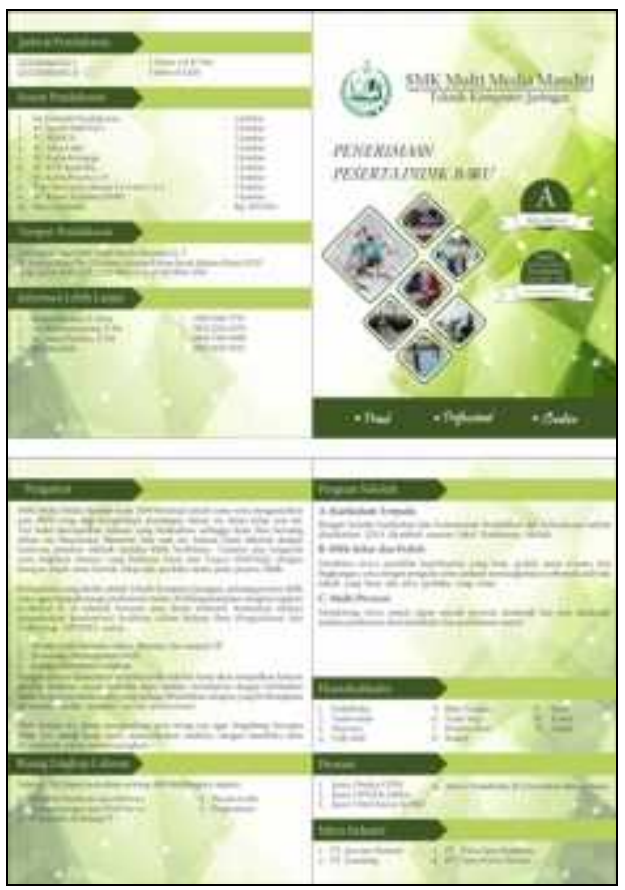

Gambar 11. Brosur

Gambar 11 adalah brosur, merupakan media promosi yang berisi informasi mengenai SMK Multimedia Mandiri seperti ruang lingkup sekolah, program sekolah, ekstrakulikuler, prestasi, mitra industri, jadwal pendaftaran, syarat pendaftaran, tempat pendaftaran, dan kontak yang dapat dihubungi untuk mengetahui informasi lebih lanjut yang ditujukan kepada masyarakat luas. Brosur dibuat menggunakan bahan Flexi Korea dengan ukuran 30 X 42 CM.

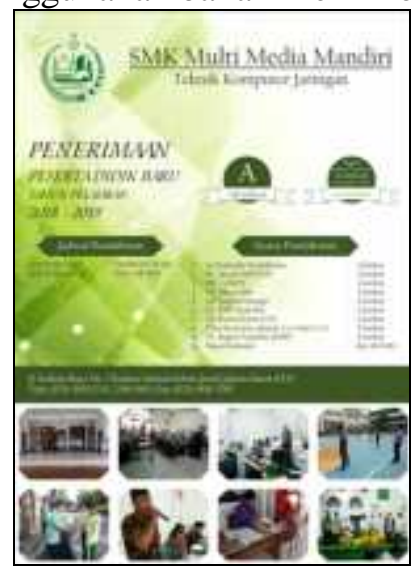

Gambar 12. Flyer

Gambar 12 flyer yang digunakan untuk menarik minat masyarakat untuk mengetahui informasi mengenai SMK Multimedia Mandiri yang dicetak di satu sisi kertas sebagai media promosi yang efektif dan efisien. Dalam flyer berisi informasi mengenai penerimaan peserta didik baru, status akreditasi, tawaran beasiswa, jadwal pendaftaran, syarat pendaftaran, alamat sekolah, nomor telepon yang dapat dihubungi, serta terdapat kumpulan foto kegiatan yang dilakukan di SMK Multimedia Mandiri. Flyer dibuat dengan bahan Flexi Korea berukuran $21 \mathrm{X}$ 29,7 CM. 


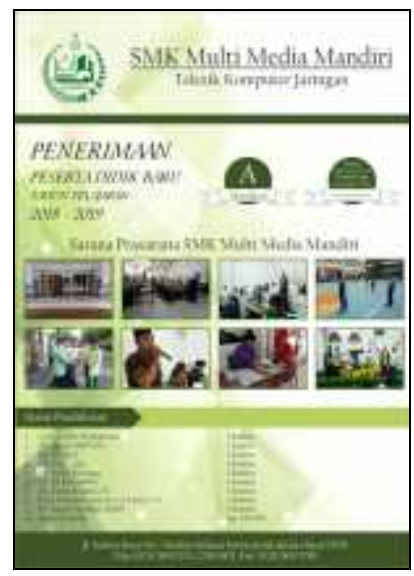

Gambar 13. Pamflet

Gambar 13 pamflet merupakan media promosi yang berisi informasi mengenai SMK Multimedia Mandiri untuk menarik minat masyarakat agar mendaftar di SMK Multimedia Mandiri, informasi yang terdapat pada pamflet yaitu penerimaan peserta didik baru, status akreditasi, beasiswa, syarat pendaftaran, alamat sekolah, dan nomor telepon yang dapat dihubungi. Selain informasi tersebut, terdapat beberapa gambar sarana dan prasarana yang ada pada SMK Multimedia Mandiri untuk memberikan gambaran kepada masyarakat luas. Pamflet dibuat dengan bahan Flexi Korea berukuran 21 X 29,7 CM.

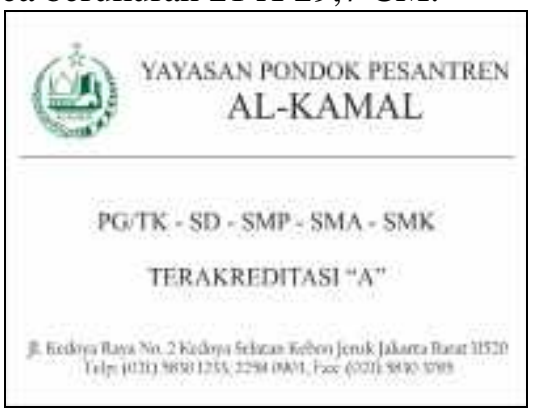

Gambar 14. Papan Nama

Gambar 14 papan nama bukanlah sebagai media promosi, melainkan papan yang digunakan untuk menunjukkan adanya sebuah sekolah yang umumnya diletakkan di depan sekolah dan menjadi identitas SMK Multimedia Mandiri. Papan nama dibuat dengan menggunakan bahan plat stainless dan mempunyai ukuran 120 X 90 CM.

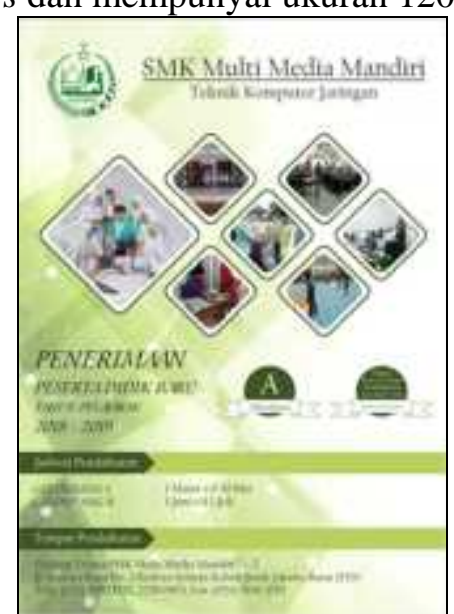

Gambar 15. Poster 
Gambar 15 poster merupakan media promosi yang bertujuan untuk menarik minat masyarakat luas untuk mendaftar di SMK Multimedia Mandiri serta memberikan informasi mengenai penerimaan peserta didik baru yang akan dipasang di tempat umum yang sering dilihat oleh khalayak ramai. Poster dibuat dengan ukuran 21 X 29,7 CM menggunakan bahan Flexi Korea.

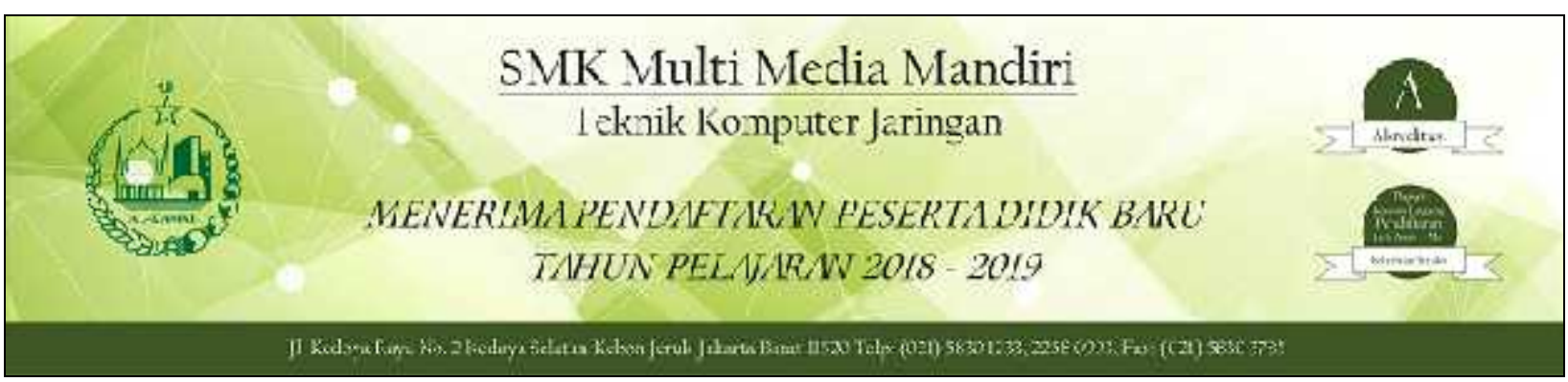

Gambar 16. Spanduk

Gambar 16 adalah spanduk yang digunakan untuk memberikan informasi pendaftaran peserta didik baru tahun ajaran 2018 - 2019 yang diadakan oleh SMK Multimedia Mandiri sebagai sarana promosi agar menarik minat masyarakat luas untuk mendaftar di SMK Multi Media Mandiri. Selain informasi pendaftaran, terdapat juga informasi akreditasi dan beasiswa serta alamat dan nomor telepon yang dapat dihubungi. Spanduk dibuat dengan ukuran 50 X 11.5 cm menggunakan bahan Flexi Korea.

\section{KESIMPULAN}

Media komunikasi visual sebagai penunjang promosi pada SMK Multi Media Mandiri dibuat untuk menarik siswa/i baru yang tentunya memerlukan media pendukung dan suatu identitas dalam promosinya. Media promosi yang efektif untuk memberikan informasi serta utuk mempromosikan SMK Multi Media Mandiri ini berbentuk media komunikasi visual yang berupa baliho, banner, flyer, pamflet, papan nama, poster, dan spanduk. Media komunikasi visual ini mempunyai pengaruh yang sangat besar penyampaian informasi yang diperlukan masyarakat maupun guru, staff, dan siswa/i SMK Multi Media Mandiri. Dengan dikembangkannya media komunikasi visual disini diharapkan dapat mendukung sarana promosi untuk meningkatkan jumlah calonsiswa/i yang akan mendaftar di tahun berikutnya dan dapat memenuhi informasi yang dibutuhkan oleh masyarakat.

\section{SARAN}

Setelah melihat kembali isi dari penelitian ini, ada beberapa saran yang dapat menjadi masukan untuk penelitian yang akan dibuat nantinya, seperti membuat media promosi yang lainnya yang diharapkan dapat membantu meningkatkan kegiatan promosi pada SMK Multi Media Mandiri, serta melakukan redesign setiap tahunnya pada design yang sudah ada sebagai bentuk penyegaran agar tidak terlihat membosankan.

\section{UCAPAN TERIMA KASIH}

Terima Kasih kepada rekan-rekan STMIK Raharja yang telah mendukung dalam penelitian ini dan memberikan masukan-masukan yang positif. 


\section{DAFTAR PUSTAKA}

[1] Lupiyoadi, Rambat, 2013, Manajemen Pemasaran Jasa, Edisi Ketiga, Salemba Empat : Jakarta.

[2] Jatmoko, Dwi, 2013, Relevansi Kurikulum SMK Kompetensi Keahlian Teknik Kendaraan Ringan Terhadap Kebutuhan Dunia Industri di Kabupaten Sleman, Vol. 3 No. 1, Jurnal Pendidikan Vokasi, Prodi PTK Pascasarjana UNY Yogyakarta.

[3] Desrianti, Dewi Immaniar, Reni Mulyani, dan Fitria Arnita, 2017, Desain Komunikasi Visual Sebagai Sarana Promosi Perguruan Tinggi, Vol. 10 No. 2, Jurnal CCIT, STMIK Raharja, Tangerang.

[4] Triyono, Kemal Salahuddin, Hendi Setiawan, 2017, Desain Media Komunikasi Visual Penunjang Event Wisuda, Vol. 10 No. 1, Jurnal CCIT, STMIK Raharja, Tangerang.

[5] Sunarya, Lusyani, Desi Wahyu Kartika Sari, Pajrin Wurika Sahara, 2016, Perancangan Media Iklan Sebagai Penunjang Informasi dan Promosi Pada Hotel Sitamiang 2 Bogor, Vol. 2 No. 1, Jurnal ICIT, STMIK Raharja, Tangerang.

[6] Desrianti, Dewi Immaniar, Anita B Wandanaya, Asih Sumaryani, 2014, Perancangan Media Katalog Sebagai Penunjang Informasi dan Promosi Pada CV. Zero Store, Vol. 7 No. 2, Jurnal CCIT, STMIK Raharja, Tangerang.

[7] Wandanaya, Anita B, Dewi Immaniar, Maryana Astuti, 2014, Design Visualisasi Logo Sebagai Identity Programs di Divisi Raharja Enrichment Centre, Vol. 8 No. 1, Jurnal CCIT, STMIK Raharja, Tangerang. 